OPEN ACCESS

Edited by:

Hui Peng,

University of Science and Technology

of China, China

Reviewed by:

Jianhua $Y u$,

City of Hope National Medical Center,

United States

Cai Zhang,

Shandong University, China

*Correspondence:

Yongjun Jiang

jiangjun55555@163.com

Specialty section:

This article was submitted to

Viral Immunology,

a section of the journal

Frontiers in Immunology

Received: 24 December 2021

Accepted: 14 February 2022

Published: 07 March 2022

Citation:

Sun Y, Zhou J and Jiang Y (2022) Negative Regulation and Protective Function of Natural Killer Cells in HIV

Infection: Two Sides of a Coin.

Front. Immunol. 13:842831. doi: 10.3389/fimmu.2022.842831

\section{Negative Regulation and Protective Function of Natural Killer Cells in HIV Infection: Two Sides of a Coin}

\author{
Yu Sun, Jie Zhou and Yongjun Jiang * \\ National Health and Family Planning Commission (NHC) Key Laboratory of AIDS Immunology (China Medical University), National \\ Clinical Research Center for Laboratory Medicine, The First Affiliated Hospital of China Medical University, Shenyang, China
}

Natural killer (NK) cells play an important immunologic role, targeting tumors and virusinfected cells; however, NK cells do not impede the progression of human immunodeficiency virus (HIV) infection. In HIV infection, NK cells exhibit impaired functions and negatively regulate other immune cell responses, although NK cells can kill HIV-infected cells and thereby suppress HIV replication. Considerable recent research has emerged regarding NK cells in the areas of immune checkpoints, negative regulation, antibody-dependent cell-mediated cytotoxicity and HIV reservoirs during HIV infection; however, no overall summary of these factors is available. This review focuses on several important aspects of NK cells in relation to HIV infection, including changes in NK cell count, subpopulations, and immune checkpoints, as well as abnormalities in NK cell functions and NK cell negative regulation. The protective function of NK cells in inhibiting HIV replication to reduce the viral reservoir and approaches for enhancing NK cell functions are also summarized.

Keywords: HIV, natural killer cells, HIV reservoir, negative regulation, immune receptors, CAR-NK

\section{INTRODUCTION}

Natural killer (NK) cells are large granular lymphocytes and the first line of defense against tumors and viral infection (1-3). NK cells include three common subpopulation groups: $\mathrm{CD} 56^{\text {bright }} \mathrm{CD} 16^{\text {neg/pos }}$ subpopulation, which primarily secrete cytokines, the $\mathrm{CD} 56^{\mathrm{dim}} \mathrm{CD} 16^{\text {pos }}$ subpopulation, which exerts toxic effects, and the dysfunctional $\mathrm{CD} 56^{\mathrm{neg}} \mathrm{CD} 16^{\mathrm{pos}}$ subpopulation $(1,4)$. Activating receptors (NCRs, NKG2C, NKG2D, etc.) and inhibitory receptors (IKIR, NKG2A, PD-1, TIGIT, etc.) are expressed on the surface of NK cells, and their combined activity determines the cell's function $(2,5)$. NK cells can initiate immune responses to target tumors and virus-infected cells by releasing perforin, Granzyme B, cytokines, and via Fas/Fas-L pathway (3, 6). Human immunodeficiency virus (HIV) is a retrovirus that tends to infect CD4 T cells via the viral envelope protein gp120 (7), inducing the depletion of infected CD4 T cells and bystander resting CD4 T cells (8-10). Ultimately, HIV infection functionally exhausts the immune system, leading to repeated infections and tumors, and ultimately, death. Research indicates that NK cells play a crucial role in anti-HIV immune responses (11) but fail to control HIV infection due to dysfunction or exertion of negative regulatory effects $(12,13)$. Nonetheless, NK cells are considered potentially important in the treatment of HIV infection and have even been applied to the elimination of viral reservoirs that 
harbor integrated, high-replicability proviruses in the host cellular DNA that cause rebound viremia when antiretroviral therapy (ART) is stopped $(14,15)$.

Although numerous original articles have been published regarding NK cells as related to immune-senescence, immune checkpoints, negative regulation, antibody-dependent cellmediated cytotoxicity (ADCC), and HIV reservoirs during HIV infection, an overall summary of these studies is lacking. Therefore, this review focuses on the characteristics of NK cells during HIV infection and summarizes the prospects of immunotherapies based on NK cells as means of eliminating viral reservoirs.

\section{CHANGES IN NK CELL COUNTS AND SUBPOPULATIONS IN HIV INFECTION}

\subsection{NK Cell Counts}

Considerable research indicates that NK cell counts change during HIV infection. Alter et al. found that the total number of NK cells expands in acute HIV infection (16), whereas in chronic viremic HIV infection, the total number of NK cells declines (17). Recently, Wang et al. reported that during primary infection, individuals with higher numbers of NK cells exhibit lower plasma viral loads and require a longer period for CD4 T cell numbers to decline to 500 cells/ $\mu \mathrm{l}$ (18). In addition, NK cell frequencies are negatively correlated with HIV DNA levels in patients during histone deacetylase inhibitor (HDACi) treatment $(19,20)$. Thus, the number of NK cells could serve as a predictor of HIV disease progression.

\subsection{NK Cell Subpopulations}

During acute HIV infection, CD $56{ }^{\mathrm{dim}} \mathrm{CD} 16^{\text {pos }} \mathrm{NK}$ cell subpopulations are amplified, whereas $\mathrm{CD} 56^{\text {neg }} \mathrm{CD} 16^{\text {pos }} \mathrm{NK}$ cell populations increase slightly, and $\mathrm{CD} 56^{\text {bright }} \mathrm{CD} 16^{\text {neg }} \mathrm{NK}$ cell populations are depleted early (16). During chronic HIV infection, the percentage of $\mathrm{CD} 56^{\text {neg }} \mathrm{NK}$ cells increases significantly (21). This subpopulation exhibits abnormal killing of K562 cells after recombinant IL-2 stimulation (22) and can affect the CD4 to CD8 T-cell ratio after ART; the higher the $\mathrm{CD} 56^{\text {neg }} \mathrm{CD} 16^{\text {pos }} \mathrm{NK}$ cell subpopulation proportion before ART, the lower the CD4 T cell count after ART (23). The percentage of CD56 ${ }^{\mathrm{dim}}$ NK cells decreases during chronic HIV infection $(21,24)$. In addition, normal NK cell subpopulation distributions are maintained in nonprogressive chronic HIV infection (16). Doria et al. found that early treated (ET) patients $(\leq 6$ months after infection) exhibit normal NK cell subpopulation distributions, whereas late-treated (LT) patients ( $>6$ months after infection) exhibit a higher percentage of the $\mathrm{CD} 56^{\text {neg }}$ subpopulation and lower percentage of the CD $56^{\text {bright }}$ subpopulation than ET patients (25). The above data suggest that the CD56 ${ }^{\mathrm{dim}}$ subpopulation is upregulated in acute infection and downregulated during chronic infection, whereas the $\mathrm{CD} 56^{\text {neg }}$ subpopulation is upregulated in both acute and chronic infection, resulting in reduced ability to suppress HIV. The changes in these subpopulations might be useful as potential biomarkers for predicting disease progression.

In addition to these classical subpopulations, changes in other subpopulations in HIV infection should be noted. Using semi- supervised machine learning approaches, Pohlmeyer et al. found that the $\mathrm{CD} 11 \mathrm{~b}^{\text {pos }} \mathrm{CD} 57^{\text {neg }} \mathrm{CD} 161^{\text {pos }}$ Siglec- $7^{\text {pos }} \mathrm{CD} 56^{\mathrm{dim}} \mathrm{CD} 16^{\text {pos }}$ NK cell subpopulation can be used to distinguish elite controllers from viremic non-controllers among HIV-infected individuals. The number of cells of this subpopulation declines in viremic non-controllers, and in vitro data indicate that this subpopulation secretes more IFN- $\gamma$ and CD107a compared with other $\mathrm{CD} 56{ }^{\mathrm{dim}} \mathrm{CD} 16^{\text {pos }} \mathrm{NK}$ cell subpopulations in HIV infection (26). In addition, Guo et al. found that the CXCR5 ${ }^{\text {pos }} \mathrm{NK}$ cell subpopulation accumulates in lymph nodes and is negatively correlated with HIV DNA levels (27). Moreover, Adeniji et al. found that a decrease in the percentage of the Siglec- $9{ }^{\text {pos }} \mathrm{CD} 56^{\mathrm{dim}}$ NK cells subpopulation and is negatively correlated with viral load during HIV infection. This subpopulation exhibits higher cytotoxicity, expresses higher levels of activating receptors (e.g., CD16, NKp30, and CD38) and lower levels of inhibitory receptors (e.g., TIGIT and NKG2A) compared with Siglec- $9^{\text {neg }}$ CD56 ${ }^{\mathrm{dim}} \mathrm{NK}$ cells during HIV infection (28). Thus, these subpopulations might play a role in spontaneous control of HIV infection and therefore prove useful in future HIV treatments.

\section{NK CELL DYSFUNCTION DURING HIV INFECTION}

\subsection{Inflammatory Environment Accelerates NK Cell Senescence}

HIV infection manifests as a chronic inflammatory condition, and chronic inflammation is a potential driver of immune-senescence (29). Desdín-Micó et al. recently confirmed that inflammation induces distal tissue senescence in $\mathrm{Tfam}^{\mathrm{fl} / \mathrm{fl}} \mathrm{Cd} 4^{\mathrm{Cre}}$ mice (30). Reactive oxygen species (ROS) and telomere length are key factors in determining cellular longevity $(31,32)$, and Soares et al. reported that NK cells produce increased levels of ROS and exhibit shortened telomere length in individuals with chronic HIV infection (33). In addition, Campos et al. reported an increased percentage of $\mathrm{CD} 56^{\text {neg }} \mathrm{CD} 16^{\text {pos }} \mathrm{NK}$ cells in healthy elderly individuals and lower levels of Granzyme expression compared with healthy young individuals (4). This pattern of $\mathrm{CD} 56^{\text {neg }} \mathrm{CD} 16^{\text {pos }} \mathrm{NK}$ cell expansion and dysfunction is common in HIV-infected individuals and could be indicative of immuno-senescence.

\subsection{Surface Receptor Imbalance Weakens NK Cell Functions}

In NK cells, surface receptors play an essential role in regulating homeostatic function. HIV-infected individuals exhibit an imbalance between inhibitory and activating surface receptors of NK cells, leading to NK cell dysfunction. Inhibitory receptors are generally upregulated in HIV-infected individuals, whereas activating receptors are downregulated.

\subsubsection{T-Cell Immunoreceptor With Ig and Immunoreceptor Tyrosine-Based Inhibition Motif (ITIM) Domains (TIGIT) and DNAM-1(CD226)}

Expression of TIGIT, an inhibitory receptor and classical immune checkpoint, is elevated in chronic infectious diseases or tumors 
and related to NK cell dysfunction $(34,35)$. Zhang et al. found that an increase in the number of NK cells expressing TIGIT leads to higher HIV load, and TIGIT ${ }^{\text {pos }}$ NK cells exhibit less-effective killing than TIGIT ${ }^{\text {neg }} \mathrm{NK}$ cells in HIV-infected individuals (36). In contrast to TIGIT, CD226 is an activating receptor that competes with TIGIT for the ligand, CD155, and targets HIV-infected CD4 T cells expressing the CD155 ligand (36-38). Expression of CD226 is upregulated on NK cells during HIV infection (39), and Yin et al. reported that TIGIT is specifically expressed on CD226 $6^{\text {pos }}$ NK cells during HIV infection (38). It is possible that TIGIT upregulation offsets the activation of CD226 on NK cells. Although TIGIT blockade enhances NK cell responses $(35,38)$, Vendrame et al. demonstrated that TIGIT blockade does not enhance NK cell-mediated killing of HIV-infected host cells, whereas TIGIT co-expression with multiple activation markers (CD2, 2B4, CD226, NTB-A) enhances the functional response of NK cells to tumors, cytokine activation, and virus-infected cells (40). Further studies of the function of TIGIT on NK cells during HIV infection are warranted.

\subsubsection{Programmed Cell Death 1 (PD-1)}

Previous studies demonstrated that PD-1 expression is associated with disease progression in individuals with various tumors, and blockade of the immune checkpoint molecule PD-1/PD-L1 axis was shown to exert anti-tumor effects $(41,42)$. Another study reported that the proportion of NK cells expressing PD-1 increases during HIV infection (43). Porichis et al. found that combined blockade of PD-1 and IL-10 enhances the killing capacity of NK cells in HIV infection and enhances HIVspecific auxiliary CD4 $\mathrm{T}$ cell functions, such as induction of IL-2 and IL-12 secretion (44). IL-2 also enhances HIV-specific NK cell-mediated ADCC (45).

\subsubsection{CD300a}

CD300a transmits inhibitory signals via ITIMs (46). Vitalle et al. found that CD300a is overexpressed on immature CD56 $6^{\mathrm{dim}}$ NK cells in HIV-infected individuals, and NK cell ADCC is significantly diminished due to CD300a expression; cross-linking of CD300a inhibits the CD56 ${ }^{\text {bright }}$ NK cell subpopulation more than other subpopulations (47).

\subsubsection{T-Cell Immunoglobulin Mucin Domain Molecule 3 (Tim-3)}

Expression of the inhibitory receptor Tim-3 (48) is not upregulated in $\mathrm{HIV}$-infected individuals. $\mathrm{Yu}$ et al. reported reduced Tim-3 expression on NK cells in HIV-infected individuals (49), and de Kivit et al. reported reduced Tim-3 expression on NK cells in HIV immunologic non-responders compared with immunologic responders. Low Tim-3 expression is correlated with low CD4 $\mathrm{T}$ cell counts (50). Kared et al. reported that Tim-3 expression is negatively correlated with levels of IFN- $\gamma$ secreted by NK cells after ART (51). Tim- $3^{\text {pos }}$ NK cells suppress NF- $\kappa B$ and ERK phosphorylation to reduce IFN- $\boldsymbol{\gamma}$ production, and Tim-3 blockade induces NK cells to secrete CD107a (49). Plasma levels of the Tim-3 ligand, Gal-9, significantly increase during primary HIV infection, and soluble Gal-9 triggers the downregulation of Tim-3 expression (52).

\subsubsection{NKG2A}

The NKG2A receptor inhibits NK cell function. During HIV infection, expression of NKG2A on CD56 ${ }^{\mathrm{dim}} \mathrm{NK}$ cells increases and the percentage of $\mathrm{NKG} 2 \mathrm{~A}^{\text {pos }} \mathrm{CD} 56^{\mathrm{dim}} \mathrm{NK}$ cells is negatively correlated with CD4 T cell count, in addition, NKG2A expression is further increased on CD56 ${ }^{\mathrm{dim}} \mathrm{NK}$ cells in AIDS (53). NKG2A expression on CD $56^{\text {neg }} \mathrm{NK}$ cells decreases in HIV infection (53, 54 ), and the degranulation function of $\mathrm{NKG} 2 \mathrm{~A}^{\text {neg }} \mathrm{CD} 56^{\text {neg }} \mathrm{NK}$ cells is impaired compared with NKG2 $\mathrm{A}^{\text {pos }} \mathrm{CD} 56^{\text {neg }} \mathrm{NK}$ cells (54).

\subsubsection{Natural Cytotoxicity Receptors (NCRs)}

NCRs are activating receptors and include NKp30, NKp44, and NKp46. De Maria et al. reported that in HIV-infected individuals, NK cells expressing low levels of NKp30, NKp44, and NKp46, exhibit decreased cytotoxicity against tumor cells (55). Kulkarni et al. found that HIV-infected individuals with higher NKp30 expression have a lower viral set point (56). The mechanism leading to decreased NKp30 expression could involve the significantly higher plasma levels of transforming growth factor (TGF)- $\beta$ in HIV-infected individuals $(57,58)$. Li et al. showed that NKp30 is a fungicidal receptor for NK cells; loss of NKp30 expression results in defective cytotoxicity against fungi and impaired perforin release (59). Decreased expression of NCRs diminishes NK cell activity against harmful microorganisms.

\subsubsection{NK Group 2D (NKG2D)}

NKG2D is an activating receptor that binds to the surface ligand NKG2DL to mediate the killing function of NK cells. Numerous studies have reported a general decrease in NKG2D expression in $\mathrm{HIV}$-infected individuals $(21,60)$. In addition, NKG2D expression is negatively correlated with viral set point (56), and the capacity of NK cells to kill target cells decreases with decreased NKG2D (61).

The above results indicate that inhibitory receptors (TIGIT, PD1, CD300a, NKG2A) are generally upregulated on NK cells, whereas activating receptors (NCR, NKG2D) are downregulated. Inhibitory receptors in particular might be co-expressed with activating receptors in HIV infection, thereby offsetting the function of the activating receptors. As a result, NK cell function is inhibited and the antiviral effect is impaired. Inhibitory or activating receptors might therefore prove useful as targets in HIV immunotherapy.

\subsection{Viral Proteins and Other Factors Impair NK Cell Function}

Aside from an imbalance between inhibitory and activating receptors, NK cell cytotoxicity is also affected by a series of other factors, including the inflammatory environment and levels of certain proteins in HIV-infected CD4 T cells.

\subsubsection{HIV Viral Protein U (Vpu) and HIV-Negative Factor (Nef) Mediate HIV Immune Escape}

Intercellular adhesion molecule-1 (ICAM-1) is a glycoprotein that promotes cell aggregation and inflammatory responses in HIV infection (62). ICAM-1 is reportedly correlated with NK cellmediated killing ability (63). Tremblay-McLean et al. reported that ICAM-1 expression on CD4 T cells is increased in HIV infection (64). However, the viral protein Vpu reduces both intercellular 
and surface expression of ICAM-1, which prevents NK cells from killing infected CD4 T cells (65). Nef is an auxiliary protein of HIV that mediates viral persistence by modifying the local environment around infected cells (66). Nef downregulates HLA-A and HLA-B expression by accelerating surface endocytosis to escape cytotoxic T lymphocyte killing $(67,68)$. Conversely, Nef maintains HLA-C and HLA-E expression, which inhibits the killing activity of NK cells (69). A recent study reported that HIV Vpu mediates the downregulation of HLA-C expression (70), which could induce resistance to NK cells with HLA-C-specifically activated killer cell immunoglobulin-like receptors (71).

\subsubsection{Matrix Metalloproteinases (MMPs) Drive NK Cell Exhaustion}

MMPs hydrolyze multiple constituents of the extracellular matrix to regulate various biological processes and diseases (72). Previous studies reported that MMP levels are increased in HIV-infected CD4 T cells and that MMPs induce the release of NKG2DL into the peripheral circulation, resulting in decreased expression of NKG2D on NK cells and a decrease in the killing ability of NK cells $(73,74)$.

\subsubsection{TGF- $\beta$ and Interferon-Gamma-Inducible Protein (IP)-10 Negatively Regulate NK Cells}

TGF- $\beta$ and IP-10 play key roles in controlling immune responses and regulating the activity of immune cells $(75,76)$. Plasma levels of TGF- $\beta$ are significantly increased in HIV-infected individuals $(57,77)$. Majumder et al. reported that increased TGF- $\beta$ production by $\mathrm{Vpr}+$ infected peripheral blood mononuclear cells leads to impaired ability of NK cells to lyse Vpr+ infected target cells (78). Plasma levels of IP-10 are markedly increased in HIV infection and positively associated with disease progression (7981); increased IP-10 levels lead to decreased secretion of IFN- $\gamma$ and CD107a expression by NK cells (79). IP-10 blockade could therefore be a new strategy for controlling HIV (79). In addition to the various aspects mentioned above, NK cell functions might also be affected by many other as yet unknown factors during HIV infection; thus, further study is needed. Reducing the expression of certain viral proteins and inhibiting certain elevated expression of cytokines in plasma are potential options for restoring the function of NK cells to suppress HIV infection.

\section{NK CELLS PLAY A NEGATIVE REGULATORY ROLE IN HIV INFECTION}

NK cells exert multiple biological functions. In addition to antitumor and antiviral functions, NK cells also have regulatory functions in the maintenance of immune homeostasis. Waggoner reported that NK cells acted as rheostats in a mouse model of lymphocytic choriomeningitis virus (LCMV, a model of human HIV) infection. During high-dose LCMV infection, wildtype mice exhibited an increased survival ratio, less-intense immuno-pathogenesis, and higher viral titer compared with NK cell-depleted mice. At medium doses of LCMV, infected wild-type mice exhibited higher viral titer, fewer antiviral T cells, and lower survival ratio compared with NK cell-depleted mice (82). The regulatory functions of NK cells inhibit immunopathogenesis in LCMV infection but enable persistent viral infection. Lang et al. also demonstrated that $\mathrm{NK}$ cells expressing higher levels of NKG2D inhibit the proliferation of CD8 T cells and IFN- $\gamma$ secretion during LCMV infection (83).

Other studies have found that peripheral blood from healthy human controls contains a small amount of regulatory NK (NKreg) cells that secrete IL-10 and inhibit the proliferation of antigenspecific CD4 T cells (84). In chronic Hepatitis B Virus infection, NK-reg cells secrete more IL-10, which then suppresses the proliferation of CD4 and CD8 T cells and the secretion of IFN- $\gamma$ (85). Moreover, tumor-infiltrating NK-reg cells express high levels of CD73, which promotes the production of TGF- $\beta$ and IL-10 via the STAT3 signaling pathway. CD73 ${ }^{\text {pos }}$ NK-reg cells also inhibit the activation of CD4 T cells (86). Recent research indicates that NK cells also play a negative regulatory role in HIV. Jiang et al. reported that the proportion of TGF- $\beta^{\text {pos }}$ or IL- $10^{\text {pos }} \mathrm{NK}$ cells is increased in HIV infection; in vitro experiments indicated that recombinant IL-10 and TGF- $\beta$ suppress NK cell function (13). Ma et al. further demonstrated that both the percentage and absolute number of $\mathrm{CD} 56{ }^{\text {neg }} \mathrm{CD} 16^{\text {pos }} \mathrm{NK}$ cells are higher in $\mathrm{HIV}$-infected individuals and that $\mathrm{CD} 56^{\text {neg }} \mathrm{CD} 16^{\text {pos }} \mathrm{NK}$ cell subpopulations secrete higher levels of TGF- $\beta$ and IL-10; in vitro experiments indicated that $\mathrm{CD} 56{ }^{\text {neg }} \mathrm{CD} 166^{\text {pos }} \mathrm{NK}$ cells from $\mathrm{HIV}$-infected individuals suppress IFN- $\gamma$ secretion by CD8 T cells. Treatment with anti-IL-10/anti-TGF- $\beta$ antibodies was shown to reverse the inhibition of $\mathrm{CD} 56{ }^{\text {neg }} \mathrm{CD} 16^{\text {pos }} \mathrm{NK}$ cells (87). Moreover, NK cells can also kill autologous CD4 T cells, thus impairing CD4 T cell function. Luo et al. reported that NK cells from HIV-infected immunologic non-responders exhibit increased killing activity against uninfected CD4 T cells in vitro (88). Additionally, Chen et al. reported that NK cells tend to kill uninfected CD4 T cells due to increased ICAM-1 expression (89).

The maintenance of homeostasis is important physiologically. HIV infection leads to over-activation of the immune system and inflammatory response, potentially resulting in immunopathogenic effects. The regulatory functions of NK cells work to prevent pathological damage, but they simultaneously inhibit the function of immune cells, thereby impeding viral clearance. Therefore, whether the regulatory effect of NK cells plays a positive or negative role during antiviral treatment should be explored further.

\section{NK CELLS CAN STILL PLAY AN IMPORTANT ROLE IN ANTIVIRAL FUNCTION}

\subsection{The Killing Effect of NK Cells}

Although NK cell function is impaired during HIV infection, it still plays a key role in the antiviral immune response. Hattori et al. demonstrated that activated NK cells exert anti-HIV effects in NOD/SCID/Jak3 null mice by directly killing HIV-infected cells (90). Increased Granzyme B content and IFN- $\gamma$ level in the 
total NK cell population have been reported in long-term nonprogressing individuals (91). Alter et al. reported that CD107a expression increased and is positively correlated with the levels of NK cell-mediated target cell lysis and viral replication in viremic HIV infection (17). NK cells also exert immunomodulatory effects via the release of CC-chemokine. Kottilil et al. reported that CC-chemokines such as CCL5 (RANTES) and CCL3 (MIP$1 \alpha)$ mediate the inhibition of HIV replication; levels of these cytokines are inversely correlated with the level of plasma viremia (92). The following possible mechanisms for NK cellmediated killing have been proposed: (i) HLA expression in HIV-infected cells decreases via a missing-self mechanism, leading to activation of NK cells (93-95), or (ii) changes in the HLA-I peptide repertoire during HIV infection function as an 'innate' mechanism that reduces the involvement of inhibitory killer cell immunoglobulin-like receptors, thereby enhancing the ability of NK cells to recognize infected cells (96).

\subsection{ADCC}

The activity of NK cells also involves ADCC, which plays a critical role in the anti-HIV immune response. It has been reported that anti-HIV IgG can be isolated from the plasma of acutely infected persons, and plasma from these patients can inhibit HIV p24 in the presence of NK cells (97). Chen et al. reported that ADCC reduces the level of viral set point in the early stages of infection, which could have great significance in disease intervention (98). ADCC is primarily mediated by NK cells via binding of the FcR- $\gamma \mathrm{III}$ (CD16) receptor with the Fc segment of antibodies bound to antigens expressed on infected cells. NK cells are activated by CD16 via signals associated with small adaptor proteins, such as FceRI- $\gamma(\mathrm{FcR} \gamma)$ and CD3- $\zeta$ (99). However, CD16 expression is not the only factor that determines the intensity of ADCC. FcR $\gamma^{\text {neg }} \mathrm{NK}$ cells expressing lower levels of CD16 compared with traditional NK cells in HIV-infected individuals exhibit enhanced ADCC after CD16 cross-linking $(100,101)$, although the mechanism remains unclear. Several approaches to increase ADCC have been reported. For example, increased IFN- $\alpha$ secretion significantly augments ADCCassociated lysis of HIV-infected target cells (102). In addition, NKG2D can assist CD16 to exert ADCC effect (103); adding alefacept (recombinant human LFA-3/IgG1) was shown to further enhance the preference of CD16.NK-92 cells for killing infected CD4 T cells (104). Bardhi et al. constructed a broadly neutralizing antibodies (bnAb) (defucosylated LSEVh-LS-F) that increases the affinity between the antibody's Fc segment and CD16 on NK cells, specifically targeting two sites: the gp120 CD4 binding site and CD4-induced gp120 co-receptor binding site, thereby enhancing ADCC in a humanized mouse model (105). This effect was also observed with another bnAb targeting the gp41 region of the HIV Env protein (106).

\subsection{Memory/Adaptive NK Cells}

The discovery of memory NK cells prompted the novel proposal of directly protecting the host by exploiting the effector function of memory NK cells (107). Nikzad et al. discovered that human NK cells segregated from the BLT (bone marrow, liver, and thymus) humanized mice vaccinated with HIV-Env exhibit vaccination dependence and mediate the specific killing of HIV-Env-loaded homogenic cells in vitro (108). The proportion of the adaptive-like CD $56^{\text {dim }} \mathrm{NK}$ cell subpopulation exhibiting high expression of CD57, NKG2C, and CD2 and low expression of FcR $\gamma$ is increased in HIV-infected individuals (109, 110). Several immunological and virological markers are improved in HIV-infected individuals with a high frequency of $\mathrm{NKG} 2 \mathrm{C}^{\text {pos }} \mathrm{CD} 57^{\text {pos }} \mathrm{NK}$ cells, including lower HIV viral load, lower IP-10 and IL-6 plasma levels, and normal mature dendritic cell counts $(111,112)$. In addition, the adaptive NK cells contribute to the efficacy of early ART, and notably, the frequency of these cells does not decline after early ART (111). Tomescu et al. reported that during the course of bnAb immunotherapy, CD57 $7^{\text {pos }}$ and $\mathrm{NKG} 2 \mathrm{C}^{\text {pos }} \mathrm{NK}$ cells are the primary ADCC effector subpopulations targeting HIV-infected CD4 T cells (113). Ma et al. reported that the percentage of $\mathrm{NKG} 2 \mathrm{~A}^{\text {neg }} \mathrm{NKG} 2 \mathrm{C}^{\text {pos }} \mathrm{NK}$ cells is negatively associated with plasma HIV RNA levels, and NKG2C ${ }^{\text {pos }} \mathrm{NK}$ cells from HIVinfected individuals were shown to inhibit the P24 antigen to a greater extent in vitro than $\mathrm{NKG} 2 \mathrm{C}^{\text {neg }} \mathrm{NK}$ cells (114). Moreover, CD57 ${ }^{\text {pos }} \mathrm{NKG} 2 \mathrm{C}^{\text {pos }} \mathrm{NK}$ cells exhibit higher OSBPL3 expression, which is generally linked to ADCC (115). Wang et al. recently reported that the frequency of $\mathrm{CD} 94^{\text {pos }} \mathrm{TCF} 7^{\text {pos }} \mathrm{CD} 56^{\text {hi }} \mathrm{NK}$ cells is increased in HIV-infected individuals enriched with transcripts related to lymphocyte memory. After IL-12/IL-15 combined stimulation, CD $94^{\text {pos }} \mathrm{CD} 56^{\text {hi }} \mathrm{NK}$ cells exhibit increased IFN- $\gamma$ production and degranulation against HIVinfected CD4 $\mathrm{T}$ cells compared with the CD56 ${ }^{\mathrm{dim}} \mathrm{NK}$ cell subpopulation (116). Expansion of this subpopulation could occur secondary to the inflammation caused by loss of homeostatic type 3 innate lymphoid cells residing in the gut $(116,117)$. NK cells kill target cells and inhibit viral replication, thereby impeding the progression of HIV infection. NK cells exhibiting properties of memory cells were discovered in recent years. These cells are characterized by a long lifespan and rapid responsiveness to HIV-infected cells. Therefore, these properties of NK cells could be exploited in future HIV treatments.

\section{NK CELL-BASED IMMUNE INTERVENTIONS PROVIDE A PROMISING STRATEGY TO OVERCOME VIRAL RESERVOIRS}

Although ART can control viral replication, dormant viruses cannot be eliminated, resulting in the formation of viral reservoirs. The difficulty of eliminating latent HIV reservoirs remains the greatest obstacle to curing HIV infection. NK cells play a critical role in suppressing viral reservoirs. Marras et al. reported that the frequency of IFN- $\gamma^{\text {pos }}$ NK cells is inversely correlated with the size of the viral reservoir, measured as the integrated HIV DNA level in HIV individuals (118). It has also been reported that the frequencies of total NK cells are negatively correlated with HIV reservoir size measured as total HIV DNA in patients treated with HDACis $(19,20,119)$. Thus, 
immunotherapies that enhance the function of NK cells or utilize engineered NK cells could become effective strategies for eliminating the HIV viral reservoir.

\subsection{Strategies for Enhancing NK Cell Function}

\subsubsection{Blocking Inhibitory Receptors for NK Cell Function}

Multiple inhibitory receptors that suppress cell function are expressed on NK cells. It has been widely reported that blockade of NK cell inhibitory receptors enhances the function of the cells in inhibiting tumor immune escape, and similar observations have been reported for HIV infection. Lisovsky et al. reported that blockade of $\mathrm{NKG} 2 \mathrm{~A}$ in vitro increases CD56 ${ }^{\text {dim }}$ NKG2A ${ }^{\text {pos }} \mathrm{NK}$ cell degranulation and secretion of IFN- $\gamma$ and CCL4 against infected CD4 T cells (120). As mentioned in Section Surface Receptor Imbalance Weakens NK Cell Functions blockade of immune checkpoints such as Siglec-9, TIGIT, PD-1, and Tim-3 also enhance the killing activity of NK cells in HIV infection $(28,38,44,49)$. Inhibitors of NK cell inhibitory receptors might thus prove useful for promoting NK cell functions in HIV infection.

\subsubsection{Specific Latency Reversal Agents (LRAs) for NK Cell Function}

Although LRAs are widely used in the treatment of virus reservoirs, some LRAs can be toxic and damage immune cells $(121,122)$. Many recent studies have explored various LRAs that enhance NK cell function. SAHA, an $\mathrm{HDACi}$, reactivates latent HIV and upregulates NKG2DLs of infected cells based on ATR kinase, thus exposing infected $\mathrm{T}$ cells to NKG2D-mediated clearance by NK cells (123). PRO, a protein kinase C agonist, activates NK cells and markedly increases CD69 and CD107a expression (122). $\mathrm{PRO} /$ romidepsin combination treatment was shown to enhance NKG2D-mediated NK cell killing of P24 targets compared with single-drug treatment (121). TLR agonists also reverse HIV latency and enhance innate antiviral immunity (124). TLR-9 agonists increase NK cell degranulation, IFN- $\gamma$ production, and HIV-specific inhibition (125). For effective suppression of viral reservoirs, it is necessary to choose an LRA that enhances NK cell effector activity.

\subsubsection{Cytokine Adjuvants for NK Cell Function}

IL-18, IL-15, IL-12, and IL-2 have been recognized to activate and enhance NK cell function $(126,127)$. Ju et al. reported that administration of IL-21 increases the frequency of NK cells in HIV-vaccinated mice (128). Garrido et al. reported that NK cells stimulated with IL-15 recognize and eliminate cells latently infected with HIV after reactivation during LRA treatment (129). Moreover, IFN- $\alpha$ reduces the HIV replication via activation of immune effector NK cells, without inhibiting CD8 $\mathrm{T}$ cell function (130). Pegylated IFN- $\alpha-2 \mathrm{a}$ enhances the cytotoxicity of NK cells, thereby suppressing viral reservoirs $(131,132)$. A possible mechanism involves binding of IFN- $\alpha$ to the IFN- $\alpha \beta$ receptor, which activates multiple downstream signaling pathways, such as STAT1/STAT4, to induce the secretion of IFN- $\boldsymbol{\gamma}$ by NK cells (133).

\subsection{Prospects for Chimeric Antigen Receptor (CAR)-NK Cell Treatment of Viral Reservoirs}

Immune cells can be engineered to express a CAR, thereby redirecting their specificity and focusing their killing capacity on a particular antigen. The basic structure of a CAR molecule includes an antigen-recognition domain comprised of an intracellular signaling domain, a transmembrane domain, an extracellular hinge domain, and a single-chain variable fragment (134). In clinical trials, Liu et al. found that CAR-NK cell therapy is effective in individuals with refractory CD19-positive cancers and does not exhibit severe toxicity (135). CAR-NK cells exhibit characteristics typical of non-engineered NK cells and are resistant to HIV infection. In addition, their use is associated with substantially fewer side effects related to toxicity compared with other treatments. Therefore, CAR-NK cells could be clinically useful for targeting and eliminating latent HIV-infected cells.

Zhen et al. (2015) constructed a triple-CAR vector comprising the CD4 $\zeta$ CAR and two antiviral genes (targeting specific HIV long terminal repeat sequences and human CCR5, respectively). This triple-CAR vector was transduced into human hematopoietic stem and progenitor cells, which differentiated into effector CAR-NK cells and CAR-T cells after transplantation into $\gamma \mathrm{c}-/-$ NSG mice. These CAR cells significantly suppressed HIV replication in vivo (136). Moreover, Lim et al. used 2,4-dinitrophenyl-conjugated antibodies as adaptor molecules to generate anti-gp160 CARNK cells that recognize various epitopes of HIV gp160 to mediate killing of target cells (137). As illustrated above, CAR-NK cells have numerous advantages that suggest they could be useful in future treatments for eliminating viral reservoirs.

\section{CONCLUSION}

With respect to HIV infection, the functions of NK cells could be thought of as "two sides of the same coin". The function of NK cells is impaired during HIV infection, and in some cases, the cells can exert negative regulatory effects on other immune cells. Nevertheless, NK cells still exert protective effects against HIV infection (Figure 1). The numbers and frequencies of various NK cell subpopulations change during HIV infection. In addition, an imbalance in the immune receptor distribution occurs, and the functions of NK cells are decreased. Furthermore, NK cells suppress the functions of $\mathrm{T}$ cells by secreting cytokines such as TGF- $\beta$ and IL-10. In contrast, NK cells are still capable of lysing HIV-infected cells and suppressing viral reservoirs via the secretion of cytokines such as IFN- $\gamma$, and in this context, NK cells are negatively associated with progression of HIV infection. The functions of NK cells can be enhanced by treatment with inhibitory receptor inhibitors, LRAs, or by cytokine stimulation. Furthermore, CAR-NK cells could be beneficial for eliminating HIV reservoirs. 


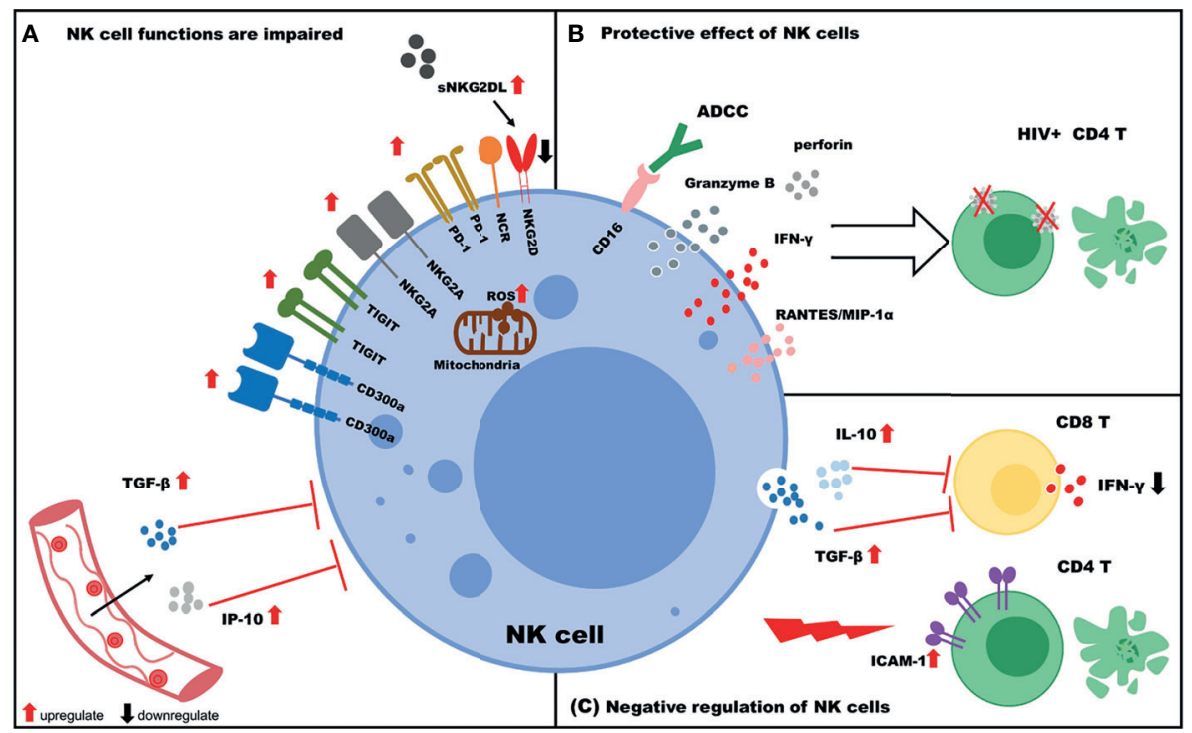

FIGURE 1 | The role of NK cells in HIV infection. (A) NK cell functions are impaired. The expression of NK cell inhibitory receptors (TIGIT, PD-1, CD300a, and NKG2A) is upregulated, and the expression of activating receptors (NKG2D and NCR) is downregulated. Increased IP-10/TGF- $\beta$ levels in plasma negatively regulate NK cell functions. In addition, increased levels of soluble NKG2DL (SNKG2DL) lead to downregulation of NKG2D expression on NK cells. (B) Protective effect of NK cells. NK cells target HIV+ CD4 T cells via ADCC or the secretion of various cytokines (IFN- $\gamma$, Granzyme B, perforin) and chemokines (RANTES, MIP-1 $\alpha$ ). (C) Negative regulation of NK cells. NK cells inhibit the function of CD8 T cells by secreting IL-10/TGF- $\beta$ and killing uninfected CD4 T cells due to high expression of ICAM-1.

\section{AUTHOR CONTRIBUTIONS}

YS wrote the manuscript. JZ collected the data. YJ provided valuable guidance and revised the manuscript. All authors contributed to the article and approved the submitted version.

\section{FUNDING}

This work is funded by National Natural Science Foundation of China (Grant Number: 82172341), and Scientific Research

\section{REFERENCES}

1. Caligiuri MA. Human Natural Killer Cells. Blood (2008) 112(3):461-9. doi: 10.1182/blood-2007-09-077438

2. Campbell KS, Hasegawa J. Natural Killer Cell Biology: An Update and Future Directions. J Allergy Clin Immunol (2020) 132(3):536-44. doi: $10.1016 /$ j.jaci.2013.07.006

3. Björkström NK, Strunz B, Ljunggren HG. Natural Killer Cells in Antiviral Immunity. Nat Rev Immunol (2021) 11:1-12. doi: 10.1038/s41577-02100558-3

4. Campos C, Pera A, Sanchez-Correa B, Alonso C, Lopez-Fernandez I, Morgado S, et al. Effect of Age and CMV on NK Cell Subpopulations. Exp Gerontol (2014) 54:130-7. doi: 10.1016/j.exger.2014.01.008

5. Chen Y, Lu D, Churov A, Fu R. Research Progress on NK Cell Receptors and Their Signaling Pathways. Mediators Inflamm (2020) 2020:6437057. doi: $10.1155 / 2020 / 6437057$

6. Brahmi Z, Hommel-Berrey G, Smith F, Thomson B. NK Cells Recover Early and Mediate Cytotoxicity via Perforin/Granzyme and Fas/Fasl Pathways in Umbilical Cord Blood Recipients. Hum Immunol (2001) 62(8):782-90. doi: 10.1016/s0198-8859(01)00275-0
Funding Project of Higher Education in Liaoning province (Grant Number: LJKZ0737).

\section{ACKNOWLEDGMENTS}

This work would like to acknowledge support from the Natural Science Foundation of China (Grant Number: 82172341), and Scientific Research Funding Project of Higher Education in Liaoning province (Grant Number: LJKZ0737).

7. Kwong PD, Wyatt R, Robinson J, Sweet RW, Sodroski J, Hendrickson WA. Structure of an HIV Gp120 Envelope Glycoprotein in Complex With the CD4 Receptor and a Neutralizing Human Antibody. Nature (1998) 393 (6686):648-59. doi: 10.1038/31405

8. Cooper A, García M, Petrovas C, Yamamoto T, Koup RA, Nabel GJ. HIV-1 Causes CD4 Cell Death Through DNA-Dependent Protein Kinase During Viral Integration. Nature (2013) 498(7454):376-9. doi: 10.1038/nature12274

9. Galloway NL, Doitsh G, Monroe KM, Yang Z, Muñoz-Arias I, Levy DN, et al. Cell-To-Cell Transmission of HIV-1 is Required to Trigger Pyroptotic Death of Lymphoid-Tissue-Derived CD4 T Cells. Cell Rep (2015) 12 (10):1555-63. doi: 10.1016/j.celrep.2015.08.011

10. Daussy CF, Galais M, Pradel B, Robert-Hebmann V, Sagnier S, Pattingre S, et al. HIV-1 Env Induces Pexophagy and an Oxidative Stress Leading to Uninfected CD4+ T Cell Death. Autophagy (2021) 17(9):2465-74. doi: $10.1080 / 15548627.2020 .1831814$

11. Altfeld M, Fadda L, Frleta D, Bhardwaj N. Dcs and NK Cells: Critical Effectors in the Immune Response to HIV-1. Nat Rev Immunol (2002) 11 (3):176-86. doi: 10.1038/nri2935

12. Ansari AW, Ahmad F, Meyer-Olson D, Kamarulzaman A, Jacobs R, Schmidt RE, et al. Natural Killer Cell Heterogeneity: Cellular Dysfunction 
and Significance in HIV-1 Immuno-Pathogenesis. Cell Mol Life Sci (2015) 72 (16):3037-49. doi: 10.1007/s00018-015-1911-5

13. Jiang Y, Yang M, Sun X, Chen X, Ma M, Yin X, et al. IL-10+ NK and TGF- $\beta+$ NK Cells Play Negative Regulatory Roles in HIV Infection. BMC Infect Dis (2018) 18(1):80. doi: 10.1186/s12879-018-2991-2

14. Desimio MG, Covino DA, Doria M. Potential of the NKG2D/NKG2DL Axis in NK Cell-Mediated Clearance of the HIV-1 Reservoir. Int J Mol Sci (2019) 20(18):4490. doi: 10.3390/ijms20184490

15. Churchill MJ, Deeks SG, Margolis DM, Siliciano RF, Swanstrom R. HIV Reservoirs: What, Where and How to Target Them. Nat Rev Microbiol (2016) 14(1):55-60. doi: 10.1038/nrmicro.2015.5

16. Alter G, Teigen N, Davis BT, Addo MM, Suscovich TJ, Waring MT, et al. Sequential Deregulation of NK Cell Subset Distribution and Function Starting in Acute HIV-1 Infection. Blood (2005) 106(10):3366-9. doi: 10.1182/blood-2005-03-1100

17. Alter G, Malenfant JM, Delabre RM, Burgett NC, Yu XG, Lichterfeld M, et al. Increased Natural Killer Cell Activity in Viremic HIV-1 Infection. J Immunol (2004) 173(8):5305-11. doi: 10.4049/jimmunol.173.8.5305

18. Wang Y, Zhang Y, Tang T, Zhao W, Fu S, Zhang Z, et al. Natural Killer Cell Counts in Primary HIV Infection Predicts Disease Progression and Immune Restoration After Treatment. Virology (2020) 550:89-98. doi: 10.1016/ j.virol.2020.08.007

19. Olesen R, Vigano S, Rasmussen TA, Søgaard OS, Ouyang Z, Buzon M, et al. Innate Immune Activity Correlates With CD4 T Cell-Associated HIV-1 DNA Decline During Latency-Reversing Treatment With Panobinostat. J Virol (2015) 89(20):10176-89. doi: 10.1128/JVI.01484-15

20. Garrido C, Tolstrup M, Søgaard OS, Rasmussen TA, Allard B, SorianoSarabia N, et al. In-Vivo Administration of Histone Deacetylase Inhibitors Does Not Impair Natural Killer Cell Function in HIV+ Individuals. AIDS (2019) 33(4):605-13. doi: 10.1097/QAD.0000000000002112

21. Jiang $\mathrm{Y}, \mathrm{He}$ L, Chen H, Bice T, Zhang Z, Liu J, et al. Alteration of Inhibitory and Activating NK Cell Receptor Expression on NK Cells in HIV-Infected Chinese. Cell Immunol (2011) 271(2):219-26. doi: 10.1016/j.cellimm. 2011.06.026

22. Mavilio D, Lombardo G, Benjamin J, Kim D, Follman D, O'Shea MA, et al. Characterization of CD56-/CD16+ Natural Killer (NK) Cells: A Highly Dysfunctional NK Subset Expanded in HIV-Infected Viremic Individuals. Proc Natl Acad Sci USA (2005) 102(8):2886-91. doi: 10.1073/ pnas.0409872102

23. Sun S, Kong W, Cui X, Lin Y, Lu B, Pan Y, et al. The Abnormal Distribution of NK Cell Subsets Before HAART Treatment may be Related to the Level of Immune Reconstitution in HIV Patient. Int Immunopharmacol (2021) 96:107784. doi: 10.1016/j.intimp.2021.107784

24. Tarazona R, Casado JG, Delarosa O, Torre-Cisneros J, Villanueva JL, Sanchez B, et al. Selective Depletion of CD56(Dim) NK Cell Subsets and Maintenance of CD56(Bright) NK Cells in Treatment-Naive HIV-1Seropositive Individuals. J Clin Immunol (2002) 22(3):176-83. doi: 10.1023/a:1015476114409

25. Doria M, Zicari S, Cotugno N, Domínguez-Rodríguez S, Ruggiero A, Pascucci GR, et al. Early ART Initiation During Infancy Preserves Natural Killer Cells in Young European Adolescents Living With HIV (CARMA Cohort). J Int AIDS Soc (2021) 24(7):e25717. doi: 10.1002/jia2.25717

26. Pohlmeyer CW, Gonzalez VD, Irrinki A, Ramirez RN, Li L, Mulato A, et al. Identification of NK Cell Subpopulations That Differentiate HIV-Infected Subject Cohorts With Diverse Levels of Virus Control. J Virol (2019) 93(7): e01790-18. doi: 10.1128/JVI.01790-18

27. Guo AL, Jiao YM, Zhao QW, Huang HH, Deng JN, Zhang C, et al. Implications of the Accumulation of CXCR5+ NK Cells in Lymph Nodes of HIV-1 Infected Patients. EBioMedicine (2021) 75:103794. doi: 10.1016/ j.ebiom.2021.103794

28. Adeniji OS, Kuri-Cervantes L, Yu C, Xu Z, Ho M, Chew GM, et al. Siglec-9 Defines and Restrains a Natural Killer Subpopulation Highly Cytotoxic to HIV-Infected Cells. PloS Pathog (2021) 17(11):e1010034. doi: 10.1371/ journal.ppat.1010034

29. Deeks SG. HIV Infection, Inflammation, Immunosenescence, and Aging. Annu Rev Med (2011) 62:141-55. doi: 10.1146/annurev-med-042909093756
30. Desdín-Micó G, Soto-Heredero G, Aranda JF, Oller J, Carrasco E, Blanco EM, et al. T Cells With Dysfunctional Mitochondria Induce Multimorbidity and Premature Senescence. Science (2020) 368(6497):1371-6. doi: 10.1126/ science.aax 0860

31. Finkel T, Holbrook NJ. Oxidants, Oxidative Stress and the Biology of Ageing. Nature (2000) 408(6809):239-47. doi: 10.1038/35041687

32. Rizvi S, Raza ST, Mahdi F. Telomere Length Variations in Aging and AgeRelated Diseases. Curr Aging Sci (2014) 7(3):161-7. doi: 10.2174/ 1874609808666150122153151

33. Soares LS, Espíndola MS, Zambuzi FA, Galvão-Lima LJ, Cacemiro MC, Soares MR, et al. Immunosenescence in Chronic HIV Infected Patients Impairs Essential Functions of Their Natural Killer Cells. Int Immunopharmacol (2020) 84:106568. doi: 10.1016/j.intimp.2020.106568

34. Zhang Q, Bi J, Zheng X, Chen Y, Wang H, Wu W, et al. Blockade of the Checkpoint Receptor TIGIT Prevents NK Cell Exhaustion and Elicits Potent Anti-Tumor Immunity. Nat Immunol (2018) 19(7):723-32. doi: 10.1038/ s41590-018-0132-0

35. Holder KA, Burt K, Grant MD. TIGIT Blockade Enhances NK Cell Activity Against Autologous HIV-1-Infected CD4+ T Cells. Clin Transl Immunol (2021) 10(10):e1348. doi: 10.1002/cti2.1348

36. Zhang X, Lu X, Cheung AKL, Zhang Q, Liu Z, Li Z, et al. Analysis of the Characteristics of TIGIT-Expressing CD3-CD56+NK Cells in Controlling Different Stages of HIV-1 Infection. Front Immunol (2021) 12:602492. doi: 10.3389/fimmu.2021.602492

37. Del Zotto G, Marcenaro E, Vacca P, Sivori S, Pende D, Moretta F, et al. Markers and Function of Human NK Cells in Normal and Pathological Conditions. Cytomet B Clin Cytom (2017) 92(2):100-14. doi: 10.1002/cyto.b.21508

38. Yi n X, Liu T, Wang Z, Ma M, Lei J, Zhang Z, et al. Expression of the Inhibitory Receptor TIGIT Is Up-Regulated Specifically on NK Cells With CD226 Activating Receptor From HIV-Infected Individuals. Front Immunol (2018) 9:2341. doi: 10.3389/fimmu.2018.02341

39. Ye X, Zhang Z, Jiang Y, Han X, Wang Y, Zhang M, et al. Expression of Human CD226 on T Cells and Natural Killer Cells and of Soluble CD226 in Plasma of HIV-1-Infected Chinese Patients. Viral Immunol (2006) 19 (3):576-81. doi: 10.1089/vim.2006.19.576

40. Vendrame E, Seiler C, Ranganath T, Zhao NQ, Vergara R, Alary M, et al. TIGIT Is Upregulated by HIV-1 Infection and Marks a Highly Functional Adaptive and Mature Subset of Natural Killer Cells. AIDS (2020) 34(6):80113. doi: $10.1097 / \mathrm{QAD} .0000000000002488$

41. Benson DMJr, Bakan CE, Mishra A, Hofmeister CC, Efebera Y, Becknell B, et al. The PD-1/PD-L1 Axis Modulates the Natural Killer Cell Versus Multiple Myeloma Effect: A Therapeutic Target for CT-011, a Novel Monoclonal Anti-PD-1 Antibody. Blood (2010) 116(13):2286-94. doi: 10.1182/blood-2010-02-271874

42. Hsu J, Hodgins JJ, Marathe M, Nicolai CJ, Bourgeois-Daigneault MC, Trevino TN, et al. Contribution of NK Cells to Immunotherapy Mediated by PD-1/PD-L1 Blockade. J Clin Invest (2018) 128(10):4654-68. doi: 10.1172/JCI99317

43. Norris S, Coleman A, Kuri-Cervantes L, Bower M, Nelson M, Goodier MR PD-1 Expression on Natural Killer Cells and CD8(+) T Cells During Chronic HIV-1 Infection. Viral Immunol (2012) 25(4):329-32. doi: 10.1089/vim.2011.0096

44. Porichis F, Hart MG, Massa A, Everett HL, Morou A, Richard J, et al. Immune Checkpoint Blockade Restores HIV-Specific CD4 T Cell Help for NK Cells. J Immunol (2018) 201(3):971-81. doi: 10.4049/jimmunol.1701551

45. Xie Z, Zheng J, Wang Y, Li D, Maermaer T, Li Y, et al. Deficient IL-2 Produced by Activated CD56+ T Cells Contributes to Impaired NK CellMediated ADCC Function in Chronic HIV-1 Infection. Front Immunol (2019) 10:1647. doi: 10.3389/fimmu.2019.01647

46. Zenarruzabeitia O, Vitallé J, Eguizabal C, Simhadri VR, Borrego F. The Biology and Disease Relevance of CD300a, an Inhibitory Receptor for Phosphatidylserine and Phosphatidylethanolamine. J Immunol (2015) 194 (11):5053-60. doi: 10.4049/jimmunol.1500304

47. Vitallé J, Terrén I, Orrantia A, Pérez-Garay R, Vidal F, Iribarren JA, et al. CD300a Inhibits CD16-Mediated NK Cell Effector Functions in HIV-1Infected Patients. Cell Mol Immunol (2019) 16(12):940-2. doi: 10.1038/ s41423-019-0275-4 
48. Wolf Y, Anderson AC, Kuchroo VK. TIM3 Comes of Age as an Inhibitory Receptor. Nat Rev Immunol (2020) 20(3):173-85. doi: 10.1038/s41577-0190224-6

49. Yu X, Lang B, Chen X, Tian Y, Qian S, Zhang Z, et al. The Inhibitory Receptor Tim-3 Fails to Suppress IFN- $\gamma$ Production via the NFAT Pathway in NK-Cell, Unlike That in CD4+ T Cells. BMC Immunol (2021) 22(1):25. doi: 10.1186/s12865-021-00417-9

50. de Kivit S, Lempsink LJ, Plants J, Martinson J, Keshavarzian A. Modulation of TIM-3 Expression on NK and T Cell Subsets in HIV Immunological NonResponders. Clin Immunol (2015) 156(1):28-35. doi: 10.1016/ j.clim.2014.10.009

51. Kared H, Martelli S, Tan SW, Simoni Y, Chong ML, Yap SH, et al. Adaptive NKG2C+CD57+ Natural Killer Cell and Tim-3 Expression During Viral Infections. Front Immunol (2018) 9:686. doi: 10.3389/fimmu.2018.00686

52. Jost S, Moreno-Nieves UY, Garcia-Beltran WF, Rands K, Reardon J, Toth I, et al. Dysregulated Tim-3 Expression on Natural Killer Cells Is Associated With Increased Galectin-9 Levels in HIV-1 Infection. Retrovirology (2013) 10:74. doi: 10.1186/1742-4690-10-74

53. Zhang R, Xu J, Hong K, Yuan L, Peng H, Tang H, et al. Increased NKG2A Found in Cytotoxic Natural Killer Subset in HIV-1 Patients With Advanced Clinical Status. AIDS (2007) 21 Suppl 8:S9-17. doi: 10.1097/ 01.aids.0000304691.32014.19

54. Zulu MZ, Naidoo KK, Mncube Z, Jaggernath M, Goulder PJR, Ndung'u T, et al. Reduced Expression of Siglec-7, NKG2A, and CD57 on Terminally Differentiated CD56-CD16+ Natural Killer Cell Subset Is Associated With Natural Killer Cell Dysfunction in Chronic HIV-1 Clade C Infection. AIDS Res Hum Retroviruses (2017) 33(12):1205-13. doi: 10.1089/AID.2017.0095

55. De Maria A, Fogli M, Costa P, Murdaca G, Puppo F, Mavilio D, et al. The Impaired NK Cell Cytolytic Function in Viremic HIV-1 Infection Is Associated With a Reduced Surface Expression of Natural Cytotoxicity Receptors (Nkp46, Nkp30 and Nkp44). Eur J Immunol (2003) 33(9):24108. doi: 10.1002/eji.200324141

56. Kulkarni AG, Paranjape RS, Thakar MR. Higher Expression of Activating Receptors on Cytotoxic NK Cells Is Associated With Early Control on HIV-1c Multiplication. Front Immunol (2014) 5:222. doi: 10.3389/ fimmu.2014.00222

57. Maina EK, Abana CZ, Bukusi EA, Sedegah M, Lartey M, Ampofo WK. Plasma Concentrations of Transforming Growth Factor Beta 1 in NonProgressive HIV-1 Infection Correlates With Markers of Disease Progression. Cytokine (2016) 81:109-16. doi: 10.1016/j.cyto.2016.02.009

58. Castriconi R, Cantoni C, Della Chiesa M, Vitale M, Marcenaro E, Conte R, et al. Transforming Growth Factor Beta 1 Inhibits Expression of Nkp30 and NKG2D Receptors: Consequences for the NK-Mediated Killing of Dendritic Cells. Proc Natl Acad Sci USA (2003) 100(7):4120-5. doi: 10.1073/pnas.0730640100

59. Li SS, Kyei SK, Timm-McCann M, Ogbomo H, Jones GJ, Shi M, et al. The NK Receptor Nkp30 Mediates Direct Fungal Recognition and Killing and Is Diminished in NK Cells From HIV-Infected Patients. Cell Host Microbe (2013) 14(4):387-97. doi: 10.1016/j.chom.2013.09.007

60. Nabatanzi R, Bayigga L, Cose S, Rowland-Jones S, Canderan G, Joloba M, et al. Aberrant Natural Killer (NK) Cell Activation and Dysfunction Among ART-Treated HIV-Infected Adults in an African Cohort. Clin Immunol (2019) 201:55-60. doi: 10.1016/j.clim.2019.02.010

61. Mavilio D, Benjamin J, Daucher M, Lombardo G, Kottilil S, Marcenaro E, et al. Natural Killer Cells in HIV-1 Infection: Dichotomous Effects of Viremia on Inhibitory and Activating Receptors and Their Functional Correlates. Proc Natl Acad Sci USA (2003) 100(25):15011-6. doi: 10.1073/pnas.2336091100

62. Yu X, Shang H, Jiang Y. ICAM-1 in HIV Infection and Underlying Mechanisms. Cytokine (2020) 125:154830. doi: 10.1016/j.cyto.2019.154830

63. Chong AS, Boussy IA, Jiang XL, Lamas M, Graf LHJr. CD54/ICAM-1 Is a Costimulator of NK Cell-Mediated Cytotoxicity. Cell Immunol (1994) 157 (1):92-105. doi: 10.1006/cimm.1994.1208

64. Tremblay-McLean A, Bruneau J, Lebouché B, Lisovsky I, Song R, Bernard NF. Expression Profiles of Ligands for Activating Natural Killer Cell Receptors on HIV Infected and Uninfected $\mathrm{CD}^{+}$T Cells. Viruses (2017) 9(10):295. doi: 10.3390/v9100295

65. Sugden SM, Pham TNQ, Cohen ÉA. HIV-1 Vpu Downmodulates ICAM-1 Expression, Resulting in Decreased Killing of Infected CD4+ T Cells by NK Cells. J Virol (2017) 91(8):e02442-16. doi: 10.1128/JVI.02442-16
66. Malim MH, Emerman M. HIV-1 Accessory Proteins-Ensuring Viral Survival in a Hostile Environment. Cell Host Microbe (2008) 3(6):388-98. doi: 10.1016/j.chom.2008.04.008

67. Schwartz O, Maréchal V, Le Gall S, Lemonnier F, Heard JM. Endocytosis of Major Histocompatibility Complex Class I Molecules Is Induced by the HIV-1 Nef Protein. Nat Med (1996) 2(3):338-42. doi: 10.1038/nm0396-338

68. Collins KL, Chen BK, Kalams SA, Walker BD, Baltimore D. HIV-1 Nef Protein Protects Infected Primary Cells Against Killing by Cytotoxic T Lymphocytes. Nature (1998) 391(6665):397-401. doi: 10.1038/34929

69. Cohen GB, Gandhi RT, Davis DM, Mandelboim O, Chen BK, Strominger JL, et al. The Selective Downregulation of Class I Major Histocompatibility Complex Proteins by HIV-1 Protects HIV-Infected Cells From NK Cells. Immunity (1999) 10(6):661-71. doi: 10.1016/s1074-7613(00)80065-5

70. Apps R, Del Prete GQ, Chatterjee P, Lara A, Brumme ZL, Brockman MA, et al. Hiv-1 Vpu Mediates Hla-C Downregulation. Cell Host Microbe (2016) 19(5):686-95. doi: 10.1016/j.chom.2016.04.005

71. Barker E, Evans DT. HLA-C Downmodulation by HIV-1 Vpu. Cell Host Microbe (2016) 19(5):570-1. doi: 10.1016/j.chom.2016.04.023

72. Visse R, Nagase H. Matrix Metalloproteinases and Tissue Inhibitors of Metalloproteinases: Structure, Function, and Biochemistry. Circ Res (2003) 92(8):827-39. doi: 10.1161/01.RES.0000070112.80711.3D

73. Nolting A, Dugast AS, Rihn S, Luteijn R, Carrington MF, Kane K, et al. MHC Class I Chain-Related Protein a Shedding in Chronic HIV-1 Infection Is Associated With Profound NK Cell Dysfunction. Virology (2010) 406(1):1220. doi: 10.1016/j.virol.2010.05.014

74. Matusali G, Tchidjou HK, Pontrelli G, Bernardi S, D'Ettorre G, Vullo V, et al. Soluble Ligands for the NKG2D Receptor Are Released During HIV-1 Infection and Impair NKG2D Expression and Cytotoxicity of NK Cells. FASEB J (2013) 27(6):2440-50. doi: 10.1096/fj.12-223057

75. Morikawa M, Derynck R, Miyazono K. Tgf- $\beta$ and the TGF- $\beta$ Family: Context-Dependent Roles in Cell and Tissue Physiology. Cold Spring Harb Perspect Biol (2016) 8(5):a021873. doi: 10.1101/cshperspect.a021873

76. Liu M, Guo S, Hibbert JM, Jain V, Singh N, Wilson NO, et al. CXCL10/IP-10 in Infectious Diseases Pathogenesis and Potential Therapeutic Implications. Cytokine Growth Factor Rev (2011) 22(3):121-30. doi: 10.1016/j.cytogfr.2011.06.001

77. Valdivia A, Ly J, Gonzalez L, Hussain P, Saing T, Islamoglu $\mathrm{H}$, et al. Restoring Cytokine Balance in HIV-Positive Individuals With Low CD4 T Cell Counts. AIDS Res Hum Retroviruses (2017) 33(9):905-18. doi: 10.1089/ AID.2016.0303

78. Majumder B, Venkatachari NJ, O'Leary S, Ayyavoo V. Infection With VprPositive Human Immunodeficiency Virus Type 1 Impairs NK Cell Function Indirectly Through Cytokine Dysregulation of Infected Target Cells. J Virol (2008) 82(14):7189-200. doi: 10.1128/JVI.01979-07

79. Wang Z, Wu T, Ma M, Zhang Z, Fu Y, Liu J, et al. Elevated Interferon- $\gamma$ Induced Protein 10 and Its Receptor CXCR3 Impair NK Cell Function During HIV Infection. J Leukoc Biol (2017) 102(1):163-70. doi: 10.1189/ jlb.5A1016-444R

80. Wang Z, Yin X, Ma M, Ge H, Lang B, Sun H, et al. IP-10 Promotes Latent HIV Infection in Resting Memory CD4+ T Cells via LIMK-Cofilin Pathway. Front Immunol (2021) 12:656663. doi: 10.3389/fimmu.2021.656663

81. Wu X, Zhang LL, Yin LB, Fu YJ, Jiang YJ, Ding HB, et al. Deregulated Microrna-21 Expression in Monocytes From HIV-Infected Patients Contributes to Elevated IP-10 Secretion in HIV Infection. Front Immunol (2017) 8:1122. doi: 10.3389/fimmu.2017.01122

82. Waggoner SN, Cornberg M, Selin LK, Welsh RM. Natural Killer Cells Act as Rheostats Modulating Antiviral T Cells. Nature (2011) 481(7381):394-8. doi: 10.1038/nature10624

83. Lang PA, Lang KS, Xu HC, Grusdat M, Parish IA, Recher M, et al. Natural Killer Cell Activation Enhances Immune Pathology and Promotes Chronic Infection by Limiting CD8+ T-Cell Immunity. Proc Natl Acad Sci USA (2012) 109(4):1210-5. doi: 10.1073/pnas.1118834109

84. Deniz G, Erten G, Kücüksezer UC, Kocacik D, Karagiannidis C, Aktas E, et al. Regulatory NK Cells Suppress Antigen-Specific T Cell Responses. J Immunol (2008) 180(2):850-7. doi: 10.4049/jimmunol.180.2.850

85. Li H, Zhai N, Wang Z, Song H, Yang Y, Cui A, et al. Regulatory NK Cells Mediated Between Immunosuppressive Monocytes and Dysfunctional T Cells in Chronic HBV Infection. Gut (2018) 67(11):2035-44. doi: 10.1136/ gutjnl-2017-314098 
86. Neo SY, Yang Y, Record J, Ma R, Chen X, Chen Z, et al. CD73 Immune Checkpoint Defines Regulatory NK Cells Within the Tumor Microenvironment. J Clin Invest (2020) 130(3):1185-98. doi: 10.1172/ JCI128895

87. Ma M, Yin X, Zhao X, Guo C, Zhu X, Liu T, et al. CD56- CD16+ NK Cells From HIV-Infected Individuals Negatively Regulate IFN- $\gamma$ Production by Autologous CD8+ T Cells. J Leukoc Biol (2019) 106(6):1313-23. doi: 10.1002/JLB.3A0819-171RR

88. Luo Z, Li Z, Martin L, Hu Z, Wu H, Wan Z, et al. Increased Natural Killer Cell Activation in HIV-Infected Immunologic Non-Responders Correlates With CD4+ T Cell Recovery After Antiretroviral Therapy and Viral Suppression. PloS One (2017) 12(1):e0167640. doi: 10.1371/ journal.pone. 0167640

89. Chen X, Chen H, Zhang Z, Fu Y, Han X, Zhang Y, et al. Elevated CD54 Expression Renders CD4+ T Cells Susceptible to Natural Killer CellMediated Killing. J Infect Dis (2019) 220(12):1892-903. doi: 10.1093/ infdis/jiz413

90. Hattori S, Matsuda K, Kariya R, Harada H, Okada S. Proliferation of Functional Human Natural Killer Cells With Anti-HIV-1 Activity in NOD/SCID/Jak3(Null) Mice. Microbiol Immunol (2016) 60(2):106-13. doi: 10.1111/1348-0421.12355

91. Jiang Y, Zhou F, Tian Y, Zhang Z, Kuang R, Liu J, et al. Higher NK Cell IFN$\gamma$ Production Is Associated With Delayed HIV Disease Progression in Ltnps. J Clin Immunol (2013) 33(8):1376-85. doi: 10.1007/s10875-013-9930-1

92. Kottilil S, Chun TW, Moir S, Liu S, McLaughlin M, Hallahan CW, et al. Innate Immunity in Human Immunodeficiency Virus Infection: Effect of Viremia on Natural Killer Cell Function. J Infect Dis (2003) 187(7):1038-45. doi: $10.1086 / 368222$

93. Kiani Z, Dupuy FP, Bruneau J, Lebouché B, Retière C, Geraghty DE, et al. The Education of NK Cells Determines Their Responsiveness to Autologous HIV-Infected CD4 T Cells. J Virol (2019) 93(23):e01185-19. doi: 10.1128/ JVI.01185-19

94. Körner C, Simoneau CR, Schommers P, Granoff M, Ziegler M, Hölzemer A, et al. HIV-1-Mediated Downmodulation of HLA-C Impacts Target Cell Recognition and Antiviral Activity of NK Cells. Cell Host Microbe (2017) 22 (1):111-9.e4. doi: 10.1016/j.chom.2017.06.008

95. Ljunggren HG, Kärre K. In Search of the 'Missing Self: MHC Molecules and NK Cell Recognition. Immunol Today (1990) 11(7):237-44. doi: 10.1016/ 0167-5699(90)90097-s

96. Ziegler MC, Nelde A, Weber JK, Schreitmüller CM, Martrus G, Huynh T, et al. HIV-1 Induced Changes in HLA-C03: 04-Presented Peptide Repertoires Lead to Reduced Engagement of Inhibitory Natural Killer Cell Receptors. AIDS (2020) 34(12):1713-23. doi: 10.1097/QAD.0000000000002596

97. Forthal DN, Landucci G, Daar ES. Antibody From Patients With Acute Human Immunodeficiency Virus (HIV) Infection Inhibits Primary Strains of HIV Type 1 in the Presence of Natural-Killer Effector Cells. J Virol (2001) 75(15):6953-61. doi: 10.1128/JVI.75.15.6953-6961.2001

98. Chen X, Lin M, Qian S, Zhang Z, Fu Y, Xu J, et al. The Early AntibodyDependent Cell-Mediated Cytotoxicity Response Is Associated With Lower Viral Set Point in Individuals With Primary HIV Infection. Front Immunol (2018) 9:2322. doi: 10.3389/fimmu.2018.02322

99. Lanier LL. Up on the Tightrope: Natural Killer Cell Activation and Inhibition. Nat Immunol (2008) 9(5):495-502. doi: 10.1038/ni1581

100. Zhou J, Amran FS, Kramski M, Angelovich TA, Elliott J, Hearps AC, et al. An NK Cell Population Lacking Fcr $\gamma$ Is Expanded in Chronically Infected HIV Patients. J Immunol (2015) 194(10):4688-97. doi: 10.4049/jimmunol. 1402448

101. Hwang I, Zhang T, Scott JM, Kim AR, Lee T, Kakarla T, et al. Identification of Human NK Cells That Are Deficient for Signaling Adaptor Fcry and Specialized for Antibody-Dependent Immune Functions. Int Immunol (2012) 24(12):793-802. doi: 10.1093/intimm/dxs080

102. Tomescu C, Tebas P, Montaner LJ. Ifn- $\alpha$ Augments Natural Killer-Mediated Antibody-Dependent Cellular Cytotoxicity of HIV-1-Infected Autologous CD4+ T Cells Regardless of Major Histocompatibility Complex Class 1 Downregulation. AIDS (2017) 31(5):613-22. doi: 10.1097/QAD. 0000000000001380

103. Parsons MS, Richard J, Lee WS, Vanderven H, Grant MD, Finzi A, et al. NKG2D Acts as a Co-Receptor for Natural Killer Cell-Mediated Anti-HIV-1
Antibody-Dependent Cellular Cytotoxicity. AIDS Res Hum Retroviruses (2016) 32(10-11):1089-96. doi: 10.1089/AID.2016.0099

104. Tomalka AG, Resto-Garay I, Campbell KS, Popkin DL. In Vitro Evidence That Combination Therapy With CD16-Bearing NK-92 Cells and FDAApproved Alefacept can Selectively Target the Latent HIV Reservoir in CD4 + CD2hi Memory T Cells. Front Immunol (2018) 9:2552. doi: 10.3389/ fimmu.2018.02552

105. Bardhi A, Wu Y, Chen W, Li W, Zhu Z, Zheng JH, et al. Potent In Vivo NK Cell-Mediated Elimination of HIV-1-Infected Cells Mobilized by a Gp120Bispecific and Hexavalent Broadly Neutralizing Fusion Protein. J Virol (2017) 91(20):e00937-17. doi: 10.1128/JVI.00937-17

106. Ramadoss NS, Zhao NQ, Richardson BA, Grant PM, Kim PS, Blish CA. Enhancing Natural Killer Cell Function With Gp41-Targeting Bispecific Antibodies to Combat HIV Infection. AIDS (2020) 34(9):1313-23. doi: 10.1097/QAD.0000000000002543

107. Lopez-Vergès S, Milush JM, Schwartz BS, Pando MJ, Jarjoura J, York VA, et al. Expansion of a Unique CD57 $7^{+}$NKG2Chi Natural Killer Cell Subset During Acute Human Cytomegalovirus Infection. Proc Natl Acad Sci USA (2011) 108(36):14725-32. doi: 10.1073/pnas.1110900108

108. Nikzad R, Angelo LS, Aviles-Padilla K, Le DT, Singh VK, Bimler L, et al. Human Natural Killer Cells Mediate Adaptive Immunity to Viral Antigens. Sci Immunol (2019) 4(35):eaat8116. doi: 10.1126/sciimmunol.aat8116

109. Peppa D, Pedroza-Pacheco I, Pellegrino P, Williams I, Maini MK, Borrow P. Adaptive Reconfiguration of Natural Killer Cells in HIV-1 Infection. Front Immunol (2018) 9:474. doi: 10.3389/fimmu.2018.00474

110. Hearps AC, Agius PA, Zhou J, Brunt S, Chachage M, Angelovich TA, et al. Persistence of Activated and Adaptive-Like NK Cells in HIV+ Individuals Despite 2 Years of Suppressive Combination Antiretroviral Therapy. Front Immunol (2017) 8:731. doi: 10.3389/fimmu.2017.00731

111. Gondois-Rey F, Chéret A, Granjeaud S, Mallet F, Bidaut G, Lécuroux C, et al. NKG2C+ Memory-Like NK Cells Contribute to the Control of HIV Viremia During Primary Infection: Optiprim-ANRS 147. Clin Transl Immunol (2017) 6(7):e150. doi: 10.1038/cti.2017.22

112. Gondois-Rey F, Chéret A, Mallet F, Bidaut G, Granjeaud S, Lécuroux C, et al. A Mature NK Profile at the Time of HIV Primary Infection Is Associated With an Early Response to Cart. Front Immunol (2017) 8:54. doi: 10.3389/ fimmu.2017.00054

113. Tomescu C, Kroll K, Colon K, Papasavvas E, Frank I, Tebas P, et al. Identification of the Predominant Human NK Cell Effector Subset Mediating ADCC Against HIV-Infected Targets Coated With Bnabs or Plasma From PLWH. Eur J Immunol (2021) 51(8):2051-61. doi: 10.1002/eji.202149188

114. Ma M, Wang Z, Chen X, Tao A, He L, Fu S, et al. NKG2C+NKG2A- Natural Killer Cells Are Associated With a Lower Viral Set Point and may Predict Disease Progression in Individuals With Primary HIV Infection. Front Immunol (2017) 8:1176. doi: 10.3389/fimmu.2017.01176

115. Costanzo MC, Kim D, Creegan M, Lal KG, Ake JA, Currier JR, et al. Transcriptomic Signatures of NK Cells Suggest Impaired Responsiveness in HIV-1 Infection and Increased Activity Post-Vaccination. Nat Commun (2018) 9(1):1212. doi: 10.1038/s41467-018-03618-w

116. Wang Y, Lifshitz L, Gellatly K, Vinton CL, Busman-Sahay K, McCauley S, et al. HIV-1-Induced Cytokines Deplete Homeostatic Innate Lymphoid Cells and Expand TCF7-Dependent Memory NK Cells. Nat Immunol (2020) 21 (3):274-86. doi: 10.1038/s41590-020-0593-9

117. Mikulak J, Di Vito C, Mavilio D. HIV-1-Induced Inflammation Shapes Innate Immunity and Induces Adaptive Traits in NK Cells. Nat Immunol (2020) 21(3):245-7. doi: 10.1038/s41590-020-0615-7

118. Marras F, Casabianca A, Bozzano F, Ascierto ML, Orlandi C, Di Biagio A, et al. Control of the HIV-1 DNA Reservoir Is Associated In Vivo and In Vitro With Nkp46/Nkp30 (CD335 CD337) Inducibility and Interferon Gamma Production by Transcriptionally Unique NK Cells. J Virol (2017) 91(23): e00647-17. doi: 10.1128/JVI.00647-17

119. Avettand-Fènoël V, Hocqueloux L, Ghosn J, Cheret A, Frange P, Melard A, et al. Total HIV-1 DNA, A Marker of Viral Reservoir Dynamics With Clinical Implications. Clin Microbiol Rev (2016) 29(4):859-80. doi: 10.1128/ CMR.00015-16

120. Lisovsky I, Isitman G, Song R, DaFonseca S, Tremblay-McLean A, Lebouché B, et al. A Higher Frequency of NKG2A+ Than of NKG2A- NK Cells Responds to Autologous HIV-Infected CD4 Cells Irrespective of Whether or 
Not They Coexpress Kir3dl1. J Virol (2015) 89(19):9909-19. doi: 10.1128/ JVI.01546-15

121. Covino DA, Desimio MG, Doria M. Combinations of Histone Deacetylase Inhibitors With Distinct Latency Reversing Agents Variably Affect HIV Reactivation and Susceptibility to NK Cell-Mediated Killing of T Cells That Exit Viral Latency. Int J Mol Sci (2021) 22(13):6654. doi: 10.3390/ ijms 22136654

122. Garrido C, Spivak AM, Soriano-Sarabia N, Checkley MA, Barker E, Karn J, et al. HIV Latency-Reversing Agents Have Diverse Effects on Natural Killer Cell Function. Front Immunol (2016) 7:356. doi: 10.3389/fimmu.2016.00356

123. Desimio MG, Giuliani E, Doria M. The Histone Deacetylase Inhibitor SAHA Simultaneously Reactivates HIV-1 From Latency and Up-Regulates NKG2D Ligands Sensitizing for Natural Killer Cell Cytotoxicity. Virology (2017) 510:9-21. doi: 10.1016/j.virol.2017.06.033

124. Macedo AB, Novis CL, Bosque A. Targeting Cellular and Tissue HIV Reservoirs With Toll-Like Receptor Agonists. Front Immunol (2019) 10:2450. doi: 10.3389/fimmu.2019.02450

125. Offersen R, Nissen SK, Rasmussen TA, Østergaard L, Denton PW, Søgaard OS, et al. A Novel Toll-Like Receptor 9 Agonist, MGN1703, Enhances HIV-1 Transcription and NK Cell-Mediated Inhibition of HIV-1-Infected Autologous CD4+ T Cells. J Virol (2016) 90(9):4441-53. doi: 10.1128/ JVI.00222-16

126. Leong JW, Chase JM, Romee R, Schneider SE, Sullivan RP, Cooper MA, et al. Preactivation With IL-12, IL-15, and IL-18 Induces CD25 and a Functional High-Affinity IL-2 Receptor on Human Cytokine-Induced Memory-Like Natural Killer Cells. Biol Blood Marrow Transplant (2014) 20(4):463-73. doi: 10.1016/j.bbmt.2014.01.006

127. Rosenberg SA, Lotze MT, Muul LM, Leitman S, Chang AE, Ettinghausen SE, et al. Observations on the Systemic Administration of Autologous Lymphokine-Activated Killer Cells and Recombinant Interleukin-2 to Patients With Metastatic Cancer. N Engl J Med (1985) 313(23):1485-92. doi: 10.1056/NEJM198512053132327

128. Ju B, Li D, Ji X, Liu J, Peng H, Wang S, et al. Interleukin-21 Administration Leads to Enhanced Antigen-Specific T Cell Responses and Natural Killer Cells in HIV-1 Vaccinated Mice. Cell Immunol (2016) 303:55-65. doi: 10.1016/j.cellimm.2016.03.006

129. Garrido C, Abad-Fernandez M, Tuyishime M, Pollara JJ, Ferrari G, SorianoSarabia N, et al. Interleukin-15-Stimulated Natural Killer Cells Clear HIV-1Infected Cells Following Latency Reversal Ex Vivo. J Virol (2018) 92(12): e00235-18. doi: 10.1128/JVI.00235-18

130. Kwaa AKR, Talana CAG, Blankson JN. Interferon Alpha Enhances NK Cell Function and the Suppressive Capacity of HIV-Specific CD8+ T Cells. J Virol (2019) 93(3):e01541-18. doi: 10.1128/JVI.01541-18
131. Hua S, Vigano S, Tse S, Zhengyu O, Harrington S, Negron J, et al. Pegylated Interferon- $\alpha$-Induced Natural Killer Cell Activation Is Associated With Human Immunodeficiency Virus-1 DNA Decline in Antiretroviral Therapy-Treated HIV-1/Hepatitis C Virus-Coinfected Patients. Clin Infect Dis (2018) 66(12):1910-7. doi: 10.1093/cid/cix1111

132. Papasavvas E, Azzoni L, Kossenkov AV, Dawany N, Morales KH, Fair M, et al. NK Response Correlates With HIV Decrease in Pegylated IFN- $\alpha 2 a-$ Treated Antiretroviral Therapy-Suppressed Subjects. J Immunol (2019) 203 (3):705-17. doi: 10.4049/jimmunol.1801511

133. Mack EA, Kallal LE, Demers DA, Biron CA. Type 1 Interferon Induction of Natural Killer Cell Gamma Interferon Production for Defense During Lymphocytic Choriomeningitis Virus Infection. mBio (2011) 2(4):e0016911. doi: $10.1128 / \mathrm{mBio} .00169-11$

134. Daher M, Rezvani K. Outlook for New CAR-Based Therapies With a Focus on CAR NK Cells: What Lies Beyond CAR-Engineered T Cells in the Race Against Cancer. Cancer Discov (2021) 11(1):45-58. doi: 10.1158/21598290.CD-20-0556

135. Liu E, Marin D, Banerjee P, Macapinlac HA, Thompson P, Basar R, et al. Use of CAR-Transduced Natural Killer Cells in CD19-Positive Lymphoid Tumors. N Engl J Med (2020) 382(6):545-53. doi: 10.1056/NEJMoa1910607

136. Zhen A, Kamata M, Rezek V, Rick J, Levin B, Kasparian S, et al. HIV-Specific Immunity Derived From Chimeric Antigen Receptor-Engineered Stem Cells. Mol Ther (2015) 23(8):1358-67. doi: 10.1038/mt.2015.102

137. Lim RM, Rong L, Zhen A, Xie J. A Universal CAR-NK Cell Targeting Various Epitopes of HIV-1 Gp160. ACS Chem Biol (2020) 15(8):2299-310. doi: 10.1021/acschembio.0c00537

Conflict of Interest: The authors declare that the research was conducted in the absence of any commercial or financial relationships that could be construed as a potential conflict of interest.

Publisher's Note: All claims expressed in this article are solely those of the authors and do not necessarily represent those of their affiliated organizations, or those of the publisher, the editors and the reviewers. Any product that may be evaluated in this article, or claim that may be made by its manufacturer, is not guaranteed or endorsed by the publisher.

Copyright (c) 2022 Sun, Zhou and Jiang. This is an open-access article distributed under the terms of the Creative Commons Attribution License (CC BY). The use, distribution or reproduction in other forums is permitted, provided the original author(s) and the copyright owner(s) are credited and that the original publication in this journal is cited, in accordance with accepted academic practice. No use, distribution or reproduction is permitted which does not comply with these terms. 